\title{
What Drives Variation in Habitat Use by Anolis Lizards: Habitat Availability or Selectivity?
}

\section{Citation}

Johnson, M. A., R. Kirby, S. Wang, and J. B. Losos. 2006. What drives variation in habitat use by Anolis lizards: habitat availability or selectivity? Canadian Journal of Zoology-Revue Canadienne De Zoologie 84, no. 6: 877-886.

\section{Published Version}

http://dx.doi.org/10.1139/Z06-068

\section{Permanent link}

http://nrs.harvard.edu/urn-3:HUL.InstRepos:2710387

\section{Terms of Use}

This article was downloaded from Harvard University's DASH repository, and is made available under the terms and conditions applicable to Other Posted Material, as set forth at http:// nrs.harvard.edu/urn-3:HUL.InstRepos:dash.current.terms-of-use\#LAA

\section{Share Your Story}

The Harvard community has made this article openly available.

Please share how this access benefits you. Submit a story.

\section{Accessibility}




\title{
What drives variation in habitat use by Anolis lizards: habitat availability or selectivity?
}

\author{
M.A. Johnson, R. Kirby, S. Wang, and J.B. Losos
}

\begin{abstract}
Geographic variation in habitat availability may drive geographic variation in a species' habitat use; alternatively, species adapted to particular habitat characteristics may use a habitat regardless of its availability within an environment. In this study, we investigated habitat use of two sympatric species of Anolis lizards that are morphologically specialized to use different microhabitats. We examined variation in microhabitat use and availability among four distinct forest types. In each forest type, we quantified available microhabitats (i.e., perch diameter, angle of inclination, and visibility), as well as microhabitats actually used by each species. We found that species consistently differed in microhabitat use, corresponding to each species' morphological specializations. However, microhabitat use of both species varied among sites. This variation in Anolis gundlachi Peters, 1876 reflected differences in microhabitat availability, while the variation in Anolis krugi Peters, 1876 resulted from differential microhabitat selectivity. These results indicate that both habitat availability and habitat preferences must be examined in multiple localities for a species to understand the causes of variation in its habitat use.
\end{abstract}

Résumé : La variation géographique de la disponibilité des habitats peut expliquer la variation géographique de l'usage qu'une espèce fait de son habitat; d'autre part, une espèce adaptée à des caractéristiques particulières de l'habitat peut utiliser un habitat quelle que soit sa disponibilité dans un milieu. Nous examinons dans notre étude l'utilisation de l'habitat par deux espèces sympatriques d'Anolis spécialisées par leur morphologie à utiliser des microhabitats différents. Nous déterminons la variation dans l'utilisation et la disponibilité des microhabitats dans quatre types distincts de forêt. Dans chaque type de forêt, nous quantifions les microhabitats disponibles (c.-à-d., diamètre des perchoirs, angle d'inclination, visibilité) ainsi que les microhabitats actuellement utilisés par chaque espèce. Les deux espèces diffèrent constamment dans leur utilisation des microhabitats, de façon qui correspond à leurs spécialisations morphologiques. L'utilisation des microhabitats varie, cependant, d'un site à un autre. Chez Anolis gundlachi Peters, 1876, cette variation résulte de la disponibilité des microhabitats, alors que chez Anolis krugi Peters, 1876 elle s'explique par une sélectivité différentielle des microhabitats. Ces résultats indiquent que la disponibilité des habitats ainsi que les préférences d'habitat doivent toutes deux être examinées en plusieurs sites pour une même espèce, si l'on veut comprendre les causes de la variation de son utilisation de l'habitat.

[Traduit par la Rédaction]

\section{Introduction}

Species with large geographical ranges often experience environmental variation across localities, and populations of widespread species may evolve adaptations in response to selective pressures in local environments. Because this differentiation may ultimately result in speciation, understanding interpopulational responses to environmental variation is a principal goal of evolutionary ecology. For example, differential habitat use within a species may reflect varying selective pressures across its range. Indeed, studies that have quantified habitat use across the geographic range of a species have shown that it can vary dramatically (e.g., Grzybowski et al. 1994; Parody and Parker 2002; Väli et al. 2004). However, individuals may dampen the effects of

Received 2 December 2005. Accepted 10 May 2006. Published on the NRC Research Press Web site at http://cjz.nrc.ca on 18 July 2006.

M.A. Johnson, ${ }^{1}$ R. Kirby, S. Wang, and J.B. Losos. Department of Biology, Washington University, Campus

Box 1229, St. Louis, MO 63130, USA.

${ }^{1}$ Corresponding author (e-mail:

mjohnson@biology2.wustl.edu). environmental variation by using a subset of the habitats available to them (e.g., Huey et al. 2003) so that habitat use remains the same even when environments differ. Therefore, to determine whether populations in different localities have different responses to environmental variation, the habitats both available to and used by a species must be quantified. In this study, we present an example of such an approach.

Variation in habitat use may result from two factors: on the one hand, a species' habitat use may mirror the distribution of habitats available; thus, populations would exhibit differences in habitat use that reflect geographic variation in the environments in which they occur. This situation may occur if the species has not evolved adaptations to a particular habitat, or if no interacting species restrict its habitat use. Conversely, a species' choice of habitat from available habitats may vary among populations so that populations occurring in similar environments would nonetheless exhibit differences in habitat use, or that populations occurring in different environments would show very similar patterns of habitat use. The former condition could be the result of population differentiation in response to differential presence of predators or competitors, or of genetic drift among populations, while the latter may occur if the species has evolved 
specialized adaptations to a particular habitat so that it will always search out that habitat, regardless of its availability. Of course, both habitat availability and habitat choice (i.e., the difference between available and used habitats) might vary geographically, leading to an interaction between the two components. Without a measure of availability, we cannot determine the cause of differential habitat use; however, studies that measure habitat availability independently of habitat use are uncommon (but see Schoener 1975; Eaton et al. 2002; Mattingly and Jayne 2004; Irschick et al. 2005).

Caribbean Anolis lizards (anoles) are an ideal system in which to address questions of habitat use across environments. Many species of anoles are widespread, occurring in environments with varying vegetative structures. However, previous work has shown that lizards in this genus have repeatedly evolved suites of specialized adaptations to particular microhabitats on the islands of the Greater Antilles (i.e., Cuba, Hispaniola, Jamaica, and Puerto Rico) (Williams 1983; Losos 1990a). For example, species that typically perch on tree trunks near the ground have long limbs and use a sit-and-wait foraging strategy, while species that perch in tall grasses and bushes have short limbs, long tails, and frequently change perches as they forage. These traits appear to be consistent across different environments in which the lizards naturally occur, but microhabitat availability in these environments has rarely been assessed (but see Schoener 1975; Mattingly and Jayne 2004; Irschick et al. 2005), and microhabitat availability and use both have not been examined in multiple environments for a given lizard species.

Lizard species that occur across a wide range of environments must either use perches with different characteristics in different localities or demonstrate different degrees of selectivity by searching out perches in each locality to maintain the same habitat use despite differences in availability. In this study, we examined microhabitat use and availability in two co-occurring Anolis species that have different habitat specializations to address two questions. First, do lizards of a single species in different environments use different microhabitats? With the abundant literature indicating that anole species have specialized adaptations to particular microhabitats (e.g., Williams 1969, 1983; Losos $1990 a, 1990 b$ ), we predicted that most characteristics of used microhabitats for each species would not differ across environments. Second, if geographic differences in microhabitat use exist, are these differences because of variation in available microhabitats, differences in choice of microhabitat, or both? For example, if a preference exists in a species to use the broadest surfaces available, then the greater the availability of broad surfaces, the greater the mean diameter used in a population. Alternatively, the species may prefer broad perch diameters in some environments more than others. Here, we provide a test to differentiate between these explanations in two species of Anolis lizards.

\section{Methods}

\section{Focal species and study sites}

To address these questions, we examined two species of sympatric Puerto Rican anoles. Anolis gundlachi Peters, 1876 (Fig. 1a) is a medium-sized "trunk-ground" lizard
Fig. 1. (a) Anolis gundlachi adult male. (b) Anolis krugi adult male.
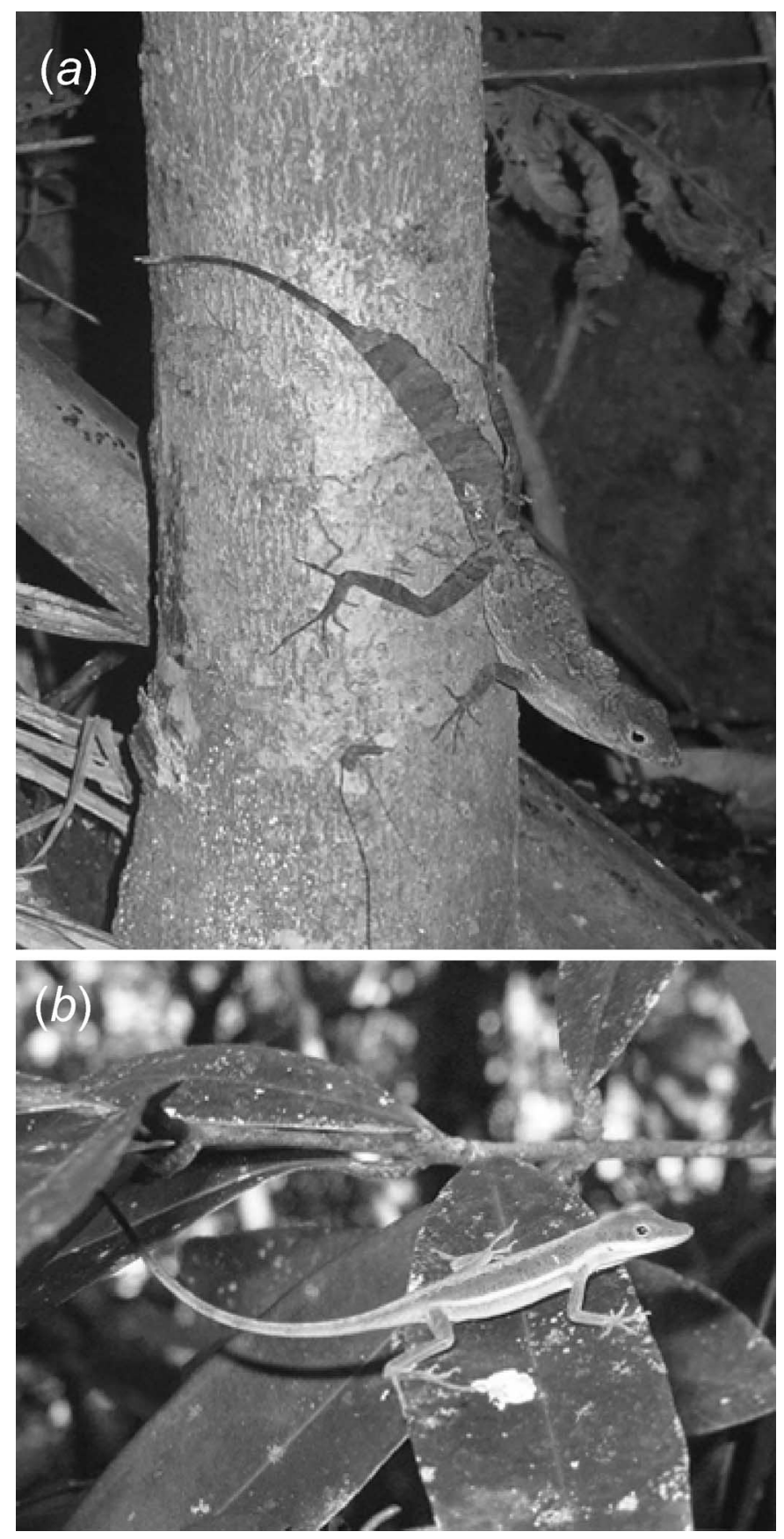

that typically perches on trunks of trees $3 \mathrm{~m}$ or below, although members of this species also descend to the ground for foraging or territory defense (Rand 1964). Anolis krugi Peters, 1876 (Fig. 1b) is a small-bodied "grass-bush" lizard with a very long tail that is most often found close to the ground in tall grass or small bushes (Rand 1964). Both of these species are common in shaded montane forests of $\mathrm{Pu}-$ erto Rico (Rivero 1998), although they have adapted to use very different microhabitats in this environment.

We conducted this study in the Caribbean National Forest (CNF) near Luquillo, Puerto Rico. Puerto Rico contains six different Holdridge life zones (Ewel and Whitmore 1973), four of which occur in the CNF and were used in this study. 
We investigated microhabitat use of A. gundlachi and A. krugi in five sites along an elevational gradient that included all four of the life zones in the CNF. Although we did not quantify lizard densities across the five sites, we observed no differences among the sites, with the exception of the apparent lower A. krugi density in the highest elevation site, i.e., cloud forest.

Tabunuco forest is a forest type within the subtropical wet forest that is dominated by the tabunuco tree (Dacryodes excelsa Vahl), but it also contains around 150 species of other trees, including tree palms, and understory vegetation. Tabunuco forest has a mean canopy height of approximately $20 \mathrm{~m}$ (Ewel and Whitmore 1973). Our study included both a "low"-elevation site ( 150 m) and a "high"-elevation site $(\sim 450 \mathrm{~m})$ in tabunuco forest. Both study species occur in each of the tabunuco study sites.

Palo colorado is a forest type within the lower montane wet forest that is characterized by palo colorado trees $(\mathrm{Cy}$ rilla spp.), as well as around 50 other species of tree palms and understory vegetation (Ewel and Whitmore 1973). Our study site in the colorado forest was at an elevation of $\sim 610 \mathrm{~m}$. Both of the study species occur at the colorado study site.

The third forest type we investigated, sierra palm forest, occurs at the intersection of three life zones. Although primarily considered lower montane wet forest, it also crosses into both subtropical wet forest and subtropical rain forest (Ewel and Whitmore 1973). It is almost exclusively dominated by a single species of palm (Prestoea montana (Graham) Andr. Hend. \& Galeano.) and has very little understory. Our site was at $\sim 800 \mathrm{~m}$ in elevation. Anolis gundlachi occurs in this palm forest study site, but A. krugi is absent in this forest probably because of the lack of understory vegetation.

The final forest type examined was cloud (also called dwarf) forest, which is characterized by a low canopy $(<7 \mathrm{~m})$. This forest type occurs only on mountain peaks in Puerto Rico, and our site occurred at $\sim 820 \mathrm{~m}$ in elevation. Cloud forest is within the lower montane rain forest zone and is distinguished by stunted trees, abundant epiphytes, and a dense herbaceous understory (Ewel and Whitmore 1973). Only A. krugi was found in this study site.

\section{Data collection}

To determine whether lizards were using a nonrandom subset of available microhabitats, we quantified both the availability of microhabitats in each study site and where the lizards were actually perching. To measure microhabitat availability we established a $30 \mathrm{~m}$ transect at each site, except in the low-elevation tabunuco forest site where we established two $25 \mathrm{~m}$ transects. Along each transect, we measured potential perches at three heights: $0.5,1.25$, and $2.0 \mathrm{~m}$. These heights encompass the typical heights of both focal species (Rand 1964; Schoener and Schoener 1971b; Losos 1990a). At $1 \mathrm{~m}$ intervals, we measured potential perches on both sides of the center transect line. If no potential perch existed within $1 \mathrm{~m}$ of the center at one of the designated heights, no perch was measured on that side. If there was more than one perch at a designated height on a particular side of the center line, we haphazardly selected one perch from those available, usually the first perch we encountered.

At each selected perch, we measured perch diameter, angle of inclination, and average visibility. Perch diameter is one of the classic measures of Anolis microhabitat (e.g., Rand 1964, 1967; Schoener and Schoener 1971a, 1971b; Pounds 1988; Losos 1990a), and previous work in birds and lizards has shown that inclination (Mattingly and Jayne 2004) and visibility (Scott et al. 1976; Eason and Stamps 1992, 2001) may affect perch use as well. Diameter was measured using a measuring tape, and angle was measured with a manual angle finder where a vertical perch was $0^{\circ}$ and a horizontal perch was $90^{\circ}$. We determined visibility by calculating the percentage of space around the perch that was free from obstructions, i.e., the percentage of space a hypothetical lizard could see. To this end, we measured visibility in the vertical (perpendicular to the ground) and horizontal (parallel to the ground) planes around the perch representing the potential position of a lizard's head. In each plane, we measured the diameter $(l)$ and distance from the perch $(h)$ of all objects, excluding the perch itself, within a $0.5 \mathrm{~m}$ radius from the position of the head. If a smaller object was directly behind a larger object, the smaller object was disregarded. For each object, we then used $h$ and $l$ to calculate the percentage of the circle around the lizard's head $(s)$ blocked by an object using the equation

$$
s=\frac{\Theta}{360^{\circ}}
$$

(For the derivation of this formula see Appendix A.) For each of the two planes, we then summed all $s$ and subtracted that value from 1 to calculate the total visibility $(V)$ in the plane, or the total proportion of the microhabitat visible to the lizard. The horizontal and vertical visibilities were then averaged for use in subsequent analyses. This visibility measure ranges from 0 to 1 , where 0 indicates a space with no visibility and 1 indicates a space completely free of obstructions to visibility.

To examine actual lizard microhabitats, we measured the perch characteristics of the first 20 adult males encountered at each site. Females were excluded from this study because males are more easily spotted in the forests, and our two focal species, like most anoles, are sexually dimorphic in morphology, ecology, and behavior (Butler et al. 2000), and have been shown to inhabit different microhabitats than conspecific males (Rand 1967; Williams 1969; Schoener and Schoener 1971b; Butler and Losos 2002). Measurements of lizard microhabitats were not taken before 0830 or after 1700 or during inclement weather, as lizards often take refuge during these periods (Losos 1990a; Hertz et al. 1993). At each lizard's perch, we measured perch height in addition to the same perch characteristics described above: diameter, angle of inclination, and mean visibility from the location of the lizard's head.

\section{Statistical analyses}

To investigate microhabitat use of lizards in different forest types, we analyzed the four perch characteristics measured: perch height, perch diameter, angle of perch inclination, and average visibility from the perch. Each variable was transformed using a method that resulted in the best ap- 
proximation of normality; height, diameter, and angle were log-transformed, and visibility was square-root-transformed. Because of the presence of zeros in the data set, a value of one was added to angle and height measures prior to transformation (Tabachnick and Fidell 2001).

To determine whether lizards used a subset of microhabitats more similar to their conspecifics in other forest types than to the mean available microhabitat in the forest type where they occur, we used a principal component analysis (PCA) in which data from both species and all five environments were pooled, followed by an analysis of variance (ANOVA) comparing PC scores among three microhabitat types (used by A. gundlachi, used by A. krugi, and available). If habitat preferences were constant, then mean PC scores for each species would cluster together regardless of the mean PC scores for each forest.

In addition, we used a series of multivariate analyses of variance (MANOVAs) described below to investigate differences in available microhabitat characteristics between forest types and differences in microhabitats used by the two species in different forest types. When significant differences were identified with MANOVA, we used follow-up ANOVAs and Tukey's honestly significant difference (HSD) post hoc tests to characterize the differences.

We used a MANOVA to compare the five forest types to one another to determine the differences in available microhabitats among the different environments. For this analysis, we used three of the four variables: perch diameter, angle of inclination, and mean visibility. (Perch height was excluded from this analysis because there are a continuous number of available heights on any given perch. Furthermore, perch height availability is not a meaningful concept when dealing with vertical tree trunks, particularly for lizards that spend all of their time within several metres of the ground. Therefore, we measured microhabitat characteristics at three predetermined heights as described above.) The two transects in low-elevation tabunuco forest were combined after we determined that results of the following analyses did not differ when data from each transect were analyzed separately. We also used a MANOVA to determine whether lizards used different microhabitats in different forest types, using all four microhabitat variables.

Finally, we performed a two-way MANOVA for each species to investigate differences between microhabitats available in the environment and microhabitats used by lizards (i.e., habitat choice), differences between each forest type, and the interaction between forest type and habitat choice. Here, a significant interaction term would signify that lizards are selecting microhabitats differently among forest types (i.e., demonstrating what we term differential selectivity).

\section{Results}

PCA

Using a PCA, we extracted all three components from the three original variables: perch diameter, angle, and visibility (Table 1). PC 1 had high positive loadings for angle and visibility and a high negative loading for diameter; PC 2 had a high positive loading for perch diameter; and PC 3 had a high negative loading for angle and a high positive loading
Table 1. Results from principal component (PC) analysis.

\begin{tabular}{|c|c|c|c|}
\hline & \multicolumn{3}{|l|}{$\mathrm{PC}$} \\
\hline & 1 & 2 & 3 \\
\hline Perch diameter & -0.596 & 0.802 & 0.035 \\
\hline Angle of inclination & 0.715 & 0.362 & -0.598 \\
\hline Visibility & 0.723 & 0.304 & 0.620 \\
\hline Eigenvalue & 1.389 & 0.866 & 0.744 \\
\hline Percent variance & 46.3 & 28.9 & 24.8 \\
\hline
\end{tabular}

Table 2. Results from ANOVAs on PC scores.

\begin{tabular}{lllr}
\hline & df & $F$ & \multicolumn{1}{l}{$P$} \\
\hline PC 1 & 2,935 & 94.09 & $<\mathbf{0 . 0 0 1}$ \\
PC 2 & 2,935 & 17.27 & $<\mathbf{0 . 0 0 1}$ \\
PC 3 & 2,935 & 3.50 & $\mathbf{0 . 0 3 1}$ \\
\hline
\end{tabular}

Note: Boldface type indicates significant $P$ values.

for visibility. We used an ANOVA comparing scores on these PC axes to examine available and used microhabitats for the different populations of both species (Table 2; Fig. 2). Tukey's HSD post hoc tests showed that all three microhabitat types (used by A. gundlachi, used by A. krugi, and available) differed at $P<0.05$ on PC 1 ; available microhabitats differed from microhabitats used by either species on PC 2, but the species did not differ from each other; and microhabitats used by $A$. krugi differed from those used by A. gundlachi and those available on PC 3, but A. gundlachi's habitat use did not differ from that available (Fig. 2).

\section{Microhabitat availability}

The distribution of available microhabitats in each forest differed significantly in diameter, angle, and visibility (Tables 3,4). (Significant differences in available microhabitats among forest types are indicated by different letters in Table $3 c$.) Because we measured perches at three predetermined heights, height was treated as a fixed factor. We found that perches at $0.5 \mathrm{~m}$ were significantly narrower, with less visibility, than perches at 1.25 and $2.0 \mathrm{~m}$. However, no significant interaction existed between height and forest type, and results did not differ when height was not included in the analysis, so we present here only results from the MANOVA in which data from all heights were pooled.

\section{Microhabitat use}

Microhabitats used by both species differed significantly among sites (Tables 3, 5). Univariate post hoc tests showed that some microhabitat dimensions differed, but not others. (Significant differences in a species' microhabitat use among forest types are indicated by different letters in Tables $3 a, 3 b$.) In particular, A. gundlachi perches differed in height and diameter, but not in angle or visibility, and A. krugi perches in different forest types differed only in visibility (Table 5).

\section{Microhabitat use vs. microhabitat availability}

We next determined if differences in microhabitat use 
Fig. 2. Principle component (PC) analysis results. Each point represents the mean $( \pm \mathrm{SE}) \mathrm{PC}$ score for each species within each forest type, as well as the mean $( \pm \mathrm{SE})$ available microhabitat within each forest type. TL is tabunuco, low elevation; TH is tabunuco, high elevation; PC is palo colorado; $\mathrm{P}$ is palm; C is cloud. (a) PC 1 vs. PC 2 ; (b) PC 1 vs. PC 3.
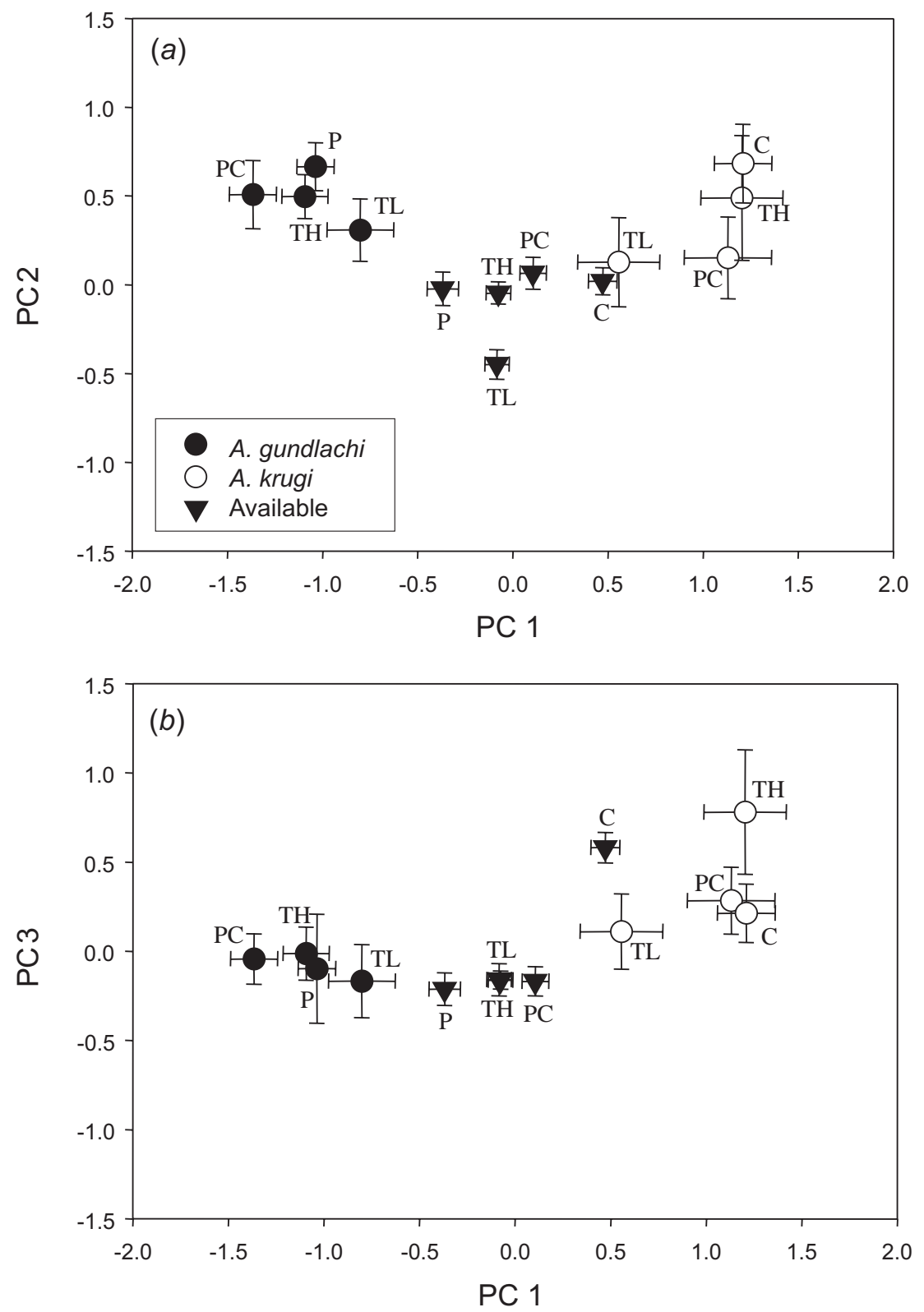

were the result of variation in availability in different forest types, or if lizards were preferentially choosing different kinds of perches in different forests. (Significant differences between the microhabitat used by a species and microhabitats available in the forest are indicated in boldface type in Tables $3 a, 3 b$.) Separate MANOVAs were performed for each species because the two species do not occur in the same set of forests. For A. gundlachi, we found that microhabitat (both available and used) differed among the forest types, microhabitats used by lizards within a forest type differed from microhabitat availability (i.e., habitat choice), and no interaction existed between forest type and habitat choice (Table 6). Subsequent ANOVAs and Tukey's HSD post hoc tests revealed that forest types differed in perch diameter and visibility, but not angle, and that A. gundlachi individuals used broader, more vertical microhabitats with greater visibility than random microhabitats in the environment (Table 7).

Available and used microhabitats were also significantly different in the forest types that contain A. krugi, the grassbush anole. Anolis krugi used a nonrandom subset of available microhabitats, and a significant interaction existed for this species between forest type and habitat choice (Table 6). Subsequent ANOVAs and Tukey's HSD post hoc tests showed that forest types differed in diameter and visibility, and that A. krugi lizards preferentially chose more horizontal perches with lower visibility than microhabitats randomly available in their environments (Table 6). Furthermore, post hoc tests showed that the forest type $\times$ habitat choice interaction in the A. krugi MANOVA was due to visibility 
Table 3. Microhabitat variables used and microhabitat available within each forest type.

\begin{tabular}{|c|c|c|c|c|c|c|c|c|c|}
\hline & \multirow[b]{2}{*}{$N$} & \multicolumn{2}{|l|}{ Diameter $(\mathrm{cm})$} & \multicolumn{2}{|l|}{ Angle $\left(^{\circ}\right)$} & \multicolumn{2}{|l|}{ Visibility } & \multicolumn{2}{|l|}{ Height $(\mathrm{m})$} \\
\hline & & Mean \pm SD & Median (range) & Mean \pm SD & Median (range) & Mean \pm SD & Median (range) & Mean \pm SD & Median (range) \\
\hline \multicolumn{10}{|c|}{ (a) Microhabitats used by Anolis gundlachi } \\
\hline \multicolumn{10}{|c|}{ Tabunuco } \\
\hline $150 \mathrm{~m}$ & 20 & $8.74 \pm 6.5 a$ & $6.5(1.2-23)$ & $10.2 \pm 12.9 \mathrm{a}$ & $6(0-50)$ & $0.91 \pm 0.13 a$ & $0.98(0.50-1)$ & $1.99 \pm 0.74 \mathrm{ab}$ & $2.03(0.9-3.4)$ \\
\hline $450 \mathrm{~m}$ & 20 & $11.46 \pm 6.3 \mathrm{ab}$ & $12.0(2.8-29)$ & $6.3 \pm 9.6 \mathrm{a}$ & $3.5(1-45)$ & $0.94 \pm 0.07 a$ & $0.96(0.70-1)$ & $1.63 \pm 0.50 \mathrm{a}$ & $1.70(0.9-2.7)$ \\
\hline Colorado $(600 \mathrm{~m})$ & 20 & $14.45 \pm 8.8 b$ & $14.0(1.5-47)$ & $8.4 \pm 13.5 a$ & $3(0-45)$ & $0.96 \pm 0.05 a$ & $0.98(0.93-1)$ & $2.37 \pm 0.78 b$ & $2.37(0.9-4.0)$ \\
\hline Palm (800 m) & 20 & $12.55 \pm 5.3 a b$ & $13.3(4.0-22)$ & $9.0 \pm 11.2 \mathrm{a}$ & $5(0-45)$ & $0.93 \pm 0.07 a$ & $0.95(0.80-1)$ & $3.53 \pm 1.50 \mathrm{c}$ & $3.15(2.3-9.4)$ \\
\hline \multicolumn{10}{|c|}{ (b) Microhabitats used by Anolis krugi } \\
\hline \multicolumn{10}{|c|}{ Tabunuco } \\
\hline $150 \mathrm{~m}$ & 21 & $5.14 \pm 8.3 \mathrm{a}$ & $1.6(0.1-35)$ & $34.0 \pm 30.1 \mathrm{a}$ & $26(0-80)$ & $0.77 \pm 0.17 \mathrm{a}$ & $0.78(0.47-0.99)$ & $0.95 \pm 0.57 \mathrm{a}$ & $0.87(0.02-2.3)$ \\
\hline $450 \mathrm{~m}$ & 13 & $5.12 \pm 8.5 \mathrm{a}$ & $3.0(0.1-32)$ & $41.8 \pm 29.4 a$ & $45(0-90)$ & $0.55 \pm 0.19 b$ & $0.52(0.14-0.79)$ & $0.64 \pm 0.83 \mathrm{a}$ & $0.29(0-2.9)$ \\
\hline Colorado $(600 \mathrm{~m})$ & 19 & $3.42 \pm 3.2 \mathrm{a}$ & $2.0(0.5-12)$ & $56.1 \pm 30.0 a$ & $65(0-90)$ & $0.63 \pm 0.16 a b$ & $0.65(0.38-0.92)$ & $0.81 \pm 0.49 \mathrm{a}$ & $0.68(0.12-1.9)$ \\
\hline Cloud (820 m) & 13 & $2.29 \pm 2.2 \mathrm{a}$ & $1.8(0.3-6)$ & $39.5 \pm 29.6 a$ & $32(4-90)$ & $0.67 \pm 0.18 \mathrm{ab}$ & $0.71(0.25-0.91)$ & $0.96 \pm 0.40 \mathrm{a}$ & $1.10(0.35-1.5)$ \\
\hline \multicolumn{10}{|c|}{ (c) Available microhabitats } \\
\hline \multicolumn{10}{|l|}{ Tabunuco } \\
\hline $150 \mathrm{~m}$ & 235 & $5.28 \pm 7.5 b c$ & $2.5(0.2-59)$ & $23.0 \pm 26.4 \mathrm{ab}$ & $11(0-90)$ & $0.87 \pm 0.13 \mathrm{ab}$ & $0.92(0.35-1)$ & & \\
\hline $450 \mathrm{~m}$ & 140 & $3.21 \pm 4.3 \mathrm{a}$ & $1.5(0.1-35)$ & $21.3 \pm 26.5 \mathrm{a}$ & $10(0-90)$ & $0.90 \pm 0.11 \mathrm{a}$ & $0.94(0.35-1)$ & & \\
\hline Colorado $(600 \mathrm{~m})$ & 143 & $4.81 \pm 5.7 \mathrm{abc}$ & $2.2(0.1-29)$ & $29.7 \pm 29.2 b$ & $21(0-90)$ & $0.85 \pm 0.12 b$ & $0.88(0.38-1)$ & & \\
\hline Palm (800 m) & 112 & $6.36 \pm 6.2 \mathrm{c}$ & $3.1(0.1-26)$ & $15.8 \pm 21.1 \mathrm{a}$ & $7(0-90)$ & $0.89 \pm 0.14 \mathrm{a}$ & $0.95(0.35-1)$ & & \\
\hline Cloud (820 m) & 162 & $4.33 \pm 6.5 \mathrm{ab}$ & $2.0(0.1-50)$ & $21.7 \pm 26.8 \mathrm{ab}$ & $9.5(0-90)$ & $0.72 \pm 0.23 \mathrm{c}$ & $0.80(0-1)$ & & \\
\hline
\end{tabular}

Note: Letters indicate results of post hoc tests; within a category $(a, b$, and $c)$ and a column, different letters indicate significant differences $(P \leq 0.05)$. Boldface type indicates that the mean used microhabitat differed $(P \leq 0.05)$ from the mean available microhabitat in a forest. 
Table 4. Results from (a) MANOVA comparing available microhabitats in each forest type and $(b)$ follow-up ANOVAs that determined which microhabitat variables differed among forest types.

\begin{tabular}{|c|c|c|c|c|}
\hline & Wilks' $\lambda$ & df & $F$ & $P$ \\
\hline Forest type & 0.804 & 12,2077 & 14.88 & $<0.001$ \\
\hline \multicolumn{5}{|c|}{ (b) ANOVA. } \\
\hline & df & $F$ & $P$ & \\
\hline Diameter & 4,787 & 6.18 & $<0.001$ & \\
\hline Angle & 4,787 & 2.67 & 0.031 & \\
\hline Visibility & 4,787 & 35.55 & $<0.001$ & \\
\hline
\end{tabular}

Note: Boldface type indicates significant $P$ values.

Table 5. Results from $(a, c)$ MANOVAs for each species and $(b, d)$ subsequent ANOVAs for each variable that determined which microhabitat variables were significantly different, within each species and among forest types.

\begin{tabular}{|c|c|c|c|c|}
\hline & Wilks' $\lambda$ & df & $F$ & $P$ \\
\hline Anolis gundlachi & 0.482 & 12,193 & 5.13 & $<0.001$ \\
\hline \multicolumn{5}{|l|}{ (b) ANOVA. } \\
\hline & df & $F$ & $P$ & \\
\hline Diameter & 3,76 & 3.61 & 0.017 & \\
\hline Angle & 3,76 & 1.07 & 0.365 & \\
\hline Visibility & 3,76 & 0.57 & 0.677 & \\
\hline Height & 3,76 & 18.47 & $<0.001$ & \\
\hline \multicolumn{5}{|l|}{ (c) MANOVA. } \\
\hline & Wilks' $\lambda$ & df & $F$ & $P$ \\
\hline Anolis krugi & 0.701 & 12,156 & 1.88 & 0.041 \\
\hline \multicolumn{5}{|l|}{ (d) ANOVA. } \\
\hline & df & $F$ & $P$ & \\
\hline Diameter & 3,62 & 0.36 & 0.702 & \\
\hline Angle & 3,62 & 1.46 & 0.233 & \\
\hline Visibility & 3,62 & 5.08 & 0.003 & \\
\hline Height & 3,62 & 1.89 & 0.140 & \\
\hline
\end{tabular}

Note: Boldface type indicates significant $P$ values.

(Table 6); A. krugi chose microhabitats with less visibility than random in three of the four forests, while choosing microhabitats at random with regard to visibility in cloud forest (the forest type that provides the lowest visibility microhabitats; Table 3). This does not indicate that the microhabitat used by A. krugi in cloud forest was significantly different with regard to visibility than the microhabitat it used in other forests (Table 3), only that in the cloud forest A. krugi used low visibility microhabitats in proportion to the availability of those microhabitats. No significant interaction existed for $A$. krugi in either diameter or angle (Table 7).

\section{Discussion}

In the present study, the five forest types we investigated differed dramatically in the structure and composition of the vegetation that they provide for perching substrates. Our quantitative measures of available microhabitats in the forests confirmed previous qualitative descriptions of these differences (Ewel and Whitmore 1973). Despite these differences, both $A$. gundlachi (a trunk-ground species) and $A$. krugi (a grass-bush species) were generally consistent in their habitat use (Fig. 2, Table 3), and consistent differences occur between the species when they occur sympatrically.

Given the differences in forest structure, however, we could predict two possible outcomes with regard to geographic variation in habitat use. On the one hand, microhabitat use may mirror availability. Alternatively, if an optimal microhabitat type exists for each species, then habitat use may not change across forests, even as availability does. This would imply that lizards actively choose a particular microhabitat type. Such selectivity is evident in the consistent nonrandom use of the two species, but this hypothesis suggests a much greater specificity at a smaller scale.

We found evidence for both patterns. In A. gundlachi, the MANOVA revealed that the difference between microhabitat availability and microhabitat use does not differ among forest types (i.e., the interaction term is nonsignificant). This result indicates that the extent of nonrandom microhabitat use by this species does not vary across environments, as lizards of this species consistently use broad, open, vertical microhabitats. Thus, differences in microhabitat use among A. gundlachi populations would seem to be a function of microhabitat availability.

Conversely, the interaction term was significant in $A$. krugi; i.e., the difference between microhabitat availability and use depended on forest type. This species chose particularly low-visibility microhabitats in some forests, whereas they were not selective and used low-visibility microhabitat in proportion to its availability in the lowest visibility forest. If differences in population density could account for these differences in microhabitat use, we would predict that individuals in a lower density population would be more selective in their habitat use, as availability of preferred habitats increases for low-density populations (Fretwell and Lucas 1970). However, the pattern observed here is the opposite; i.e., the lower density A. krugi population (cloud forest) is the least selective. Being a grass-bush anole, A. krugi exhibits adaptations for moving through narrow and cluttered habitats; these results indicate that the species prefers to use these habitats regardless of their availability. This suggests that an optimal range of microhabitat visibility exists for this species, a conclusion supported by the finding that the mean visibility of microhabitats used by $A$. krugi in cloud forest (the lowest visibility environment in this study) does not differ from the mean visibility it used in any other forest (Table 3).

This optimal range of visibility for $A$. krugi is likely bounded by two factors. First, the grass-bush microhabitats that $A$. krugi is adapted to use are by definition lower visibility than most forest microhabitats. In particular, separate stems on a bush or in a clump of grass are likely to be closer together than branches of a tree. This constraint implies that $A$. krugi are unlikely to use the most open microhabitats. However, as A. krugi are territorial animals that likely must be able see an area to defend it, there is prob- 
Table 6. Results from a two-way MANOVA for each species comparing differences in forest type, microhabitat choice, and the interaction between the two.

\begin{tabular}{lccrr}
\hline & Wilks' $\lambda$ & \multicolumn{1}{c}{ df } & \multicolumn{1}{c}{$F$} & \multicolumn{1}{c}{$P$} \\
\hline Anolis gundlachi & & & & \\
Forest type & 0.844 & 12,2278 & 12.59 & $<\mathbf{0 . 0 0 1}$ \\
Habitat choice & 0.883 & 3,861 & 38.17 & $<\mathbf{0 . 0 0 1}$ \\
Forest type $\times$ habitat choice & 0.985 & 9,2096 & 1.48 & 0.150 \\
Anolis krugi & & & & \\
Forest type & 0.928 & 12,2241 & 5.36 & $<\mathbf{0 . 0 0 1}$ \\
Habitat choice & 0.908 & 3,847 & 28.61 & $<\mathbf{0 . 0 0 1}$ \\
Forest type $\times$ habitat choice & 0.973 & 9,2061 & 2.59 & $\mathbf{0 . 0 0 6}$ \\
\hline
\end{tabular}

Note: Boldface type indicates significant $P$ values.

Table 7. Results from ANOVAs, subsequent to the MANOVA reported in Table 6 , that further investigated significant differences among forest types, habitat choice, and the interaction between the two.

\begin{tabular}{lllrr}
\hline & Variable & df & \multicolumn{1}{r}{$F$} & \multicolumn{1}{c}{$P$} \\
\hline Anolis gundlachi & & & & \\
Forest type & Diameter & 4,863 & 3.11 & $\mathbf{0 . 0 1 5}$ \\
& Angle & 4,863 & 0.37 & 0.832 \\
& Visibility & 4,863 & 35.39 & $<\mathbf{0 . 0 0 1}$ \\
Habitat choice & Diameter & 1,863 & 93.13 & $<\mathbf{0 . 0 0 1}$ \\
& Angle & 1,863 & 20.95 & $<\mathbf{0 . 0 0 1}$ \\
& Visibility & 1,863 & 19.05 & $<\mathbf{0 . 0 0 1}$ \\
Forest type $\times$ habitat choice & Diameter & 3,863 & 1.75 & 0.155 \\
& Angle & 3,863 & 1.66 & 0.174 \\
& Visibility & 3,863 & 1.75 & 0.156 \\
Anolis krugi & & & & \\
Forest type & & & & \\
& Diameter & 4,849 & 3.89 & $\mathbf{0 . 0 0 4}$ \\
Habitat choice & Angle & 4,849 & 2.31 & 0.056 \\
& Visibility & 4,849 & 11.68 & $<\mathbf{0 . 0 0 1}$ \\
& Diameter & 1,849 & 1.66 & 0.197 \\
Forest type $\times$ habitat choice & Angle & 1,849 & 23.60 & $<\mathbf{0 . 0 0 1}$ \\
& Visibility & 1,849 & 75.30 & $<\mathbf{0 . 0 0 1}$ \\
& Diameter & 3,849 & 0.24 & 0.866 \\
& Angle & 3,849 & 0.68 & 0.566 \\
& Visibility & 3,849 & 6.78 & $<\mathbf{0 . 0 0 1}$ \\
\hline
\end{tabular}

Note: Boldface type indicates significant $P$ values.

ably also a limit to the degree of low visibility that males of this species would use. In microhabitats that have too low visibility, intruders could more easily escape the detection of the territory holder (Rand 1967). Our results suggest that variation in the availability of microhabitats within this range causes $A$. krugi to exhibit differing degrees of selectivity in the different forest sites.

\section{Comparisons to other studies}

In this study, we focused on microhabitat use and its relationship to the availability of those microhabitats. Because no obvious method exists for determining the availability of perch heights across a given area, we excluded height from our analysis of microhabitat availability. However, a number of other studies have identified perch height as a variable that differs among Anolis populations in different geographic localities (e.g., Rand 1967; Jenssen 1973; Schoener 1975; Lister 1976; Irschick et al. 2005). Results from the present study concur with this finding, as we found that A. gundlachi individuals perch at greater heights at higher elevations (Tables 3, 5). Two possible explanations may explain this shift: (1) the physiological requirements of the species may require lizards in cooler forests to use higher perches to maintain their body temperatures within a preferred range (Hertz and Huey 1981; Huey 1991) and (2) the faunal composition of communities influences habitat use. Schoener (1975) argued that differential habitat use in anoles is often the direct result of the presence or absence of sympatric competitors, and perhaps A. gundlachi lizards perch higher in palm forest than in the other sites investigated because of the absence of its congener, Anolis evermanni Stejneger, 1904 (which typically uses higher perches than A. gundlachi), at the palm forest site (M.A. Johnson, personal observation). We did not find, however, that A. krugi perch heights differed across localities, although there was variation in the species with which it co-occurs. 
Previous studies have also indicated that perch diameter is a relatively plastic trait within anole species (Jenssen 1973; Irschick et al. 2005; Rodríguez-Robles et al. 2005). In this study, we also found that mean perch diameters used by A. gundlachi differed among forest types, while A. krugi did not exhibit such variation. The significance of changes in perch diameter is not clear, but two considerations may be (1) locomotor performance and (2) the evasion of predators as a function of diameter. First, the difference between the two species in this study may stem from the fact that changes in diameter are of much greater functional significance at a smaller scale. Because A. krugi is adapted to move on relatively narrow perches, it may be constrained to use perches within a small range. However, above a certain diameter, a tree trunk approximates a flat surface. Therefore, increases in diameter may not be functionally meaningful for A. gundlachi, as broader perches would not result in slower locomotion for the animal (Rodríguez-Robles et al. 2005). Indeed, most anoles avoid microhabitats where locomotive performance is submaximal (Irschick and Losos 1999). Second, anoles that perch on tree trunks, such as A. gundlachi, may more effectively avoid predators by using broader perches, as natural predators (birds) do not approach the blind side of a tree to capture prey (Scott et al. 1976). Despite some geographic differences in diameter, it is clear from the present study that both species use a nonrandom subset of the diameters available to them across all sites.

\section{Conclusions}

As the four forests examined in this study differ markedly in the lizard microhabitats they provide, results from this study suggest that Anolis species that occur in these forests have different responses (as determined by habitat use) to the differing environments in which they live. Our results demonstrate that, while microhabitat choice plays an important role in determining where a lizard will occur, important differences exist in the patterns of choice exhibited by the two species investigated here. Adaptations to particular microhabitats likely constrain habitat use in both species, dampening the effects of varying habitat availabilities across environments, but individuals of one species (A. krugi) have a different degree of preference for certain microhabitat characteristics in different environments. Habitat use therefore appears to be a complex behavioral trait, driven by both the animals' preferences and by habitat availability. Furthermore, because preferences can vary among populations in different environments, habitat use is a potentially important factor in interpopulation differentiation.

\section{Acknowledgements}

We gratefully thank Alonso Ramirez and the staff of El Verde Field Station for their logistical support and for assistance locating study sites within the forest, and Felipe Cano and Carolyn Krupp of the United States Forest Service for granting permission to work in the Caribbean National Forest. We thank Kevin McIntyre and Matthew Kirby for assistance in the field. Luke Harmon, Jason Kolbe, and Brian Langerhans provided valuable advice regarding statistical analyses, and Liam Revell and an anonymous reviewer assisted with the development of our visibility formula. Jon Chase, Luke Harmon, Jason Kolbe, Brian Langerhans, Ke- vin McIntyre, and two anonymous reviewers provided helpful comments on previous versions of the manuscript. Financial support was provided by the National Science Foundation (DEB 9982736 to J.B.L.) and the Washington University Department of Biology Summer Undergraduate Research Fellowship (to R.K.).

\section{References}

Butler, M.A., and Losos, J.B. 2002. Multivariate sexual dimorphism, sexual selection, and adaptation in Greater Antilles Anolis lizards. Ecol. Monogr. 72: 541-559.

Butler, M.A., Schoener, T.W., and Losos, J.B. 2000. The relationship between sexual size dimorphism and habitat use in Greater Antillean Anolis lizards. Evolution, 54: 259-272. PMID: 10937202.

Eason, P.K., and Stamps, J.A. 1992. The effect of visibility on territory size and shape. Behav. Ecol. 3: 166-172.

Eason, P.K., and Stamps, J.A. 2001. The effect of visibility on space use by territorial red-capped cardinals. Behaviour, 138: 19-30. doi:10.1163/156853901750077763.

Eaton, J.M., Larimer, S.C., Howard, K.G., Powell, R., and Parmerlee, J.S., Jr. 2002. Population densities and ecological release of the solitary lizard Anolis gingivinus in Anguilla, West Indies. Caribb. J. Sci. 38: 27-36.

Ewel, J.J., and Whitmore, J.L. 1973. The ecological life zones of Puerto Rico and the U.S. Virgin Islands. U.S. For. Serv. Res. Pap. ITF-18. pp. 1-72.

Fretwell, S.D., and Lucas, H.L., Jr. 1970. On territorial behavior and other factors influencing habitat distribution in birds. I. Theoretical development. Acta Biotheor. 19: 16-36.

Grzybowski, J.A., Tazik, D.J., and Schnell, G.D. 1994. Regional analysis of Black-capped vireo breeding habitats. Condor, 96: 512-544.

Hertz, P.E., and Huey, R.B. 1981. Compensation for altitudinal changes in the thermal environment by some Anolis lizards on Hispaniola. Ecology, 62: 515-521. doi:10.2307/1937714.

Hertz, P.E., Huey, R.B., and Stevenson, R.D. 1993. Evaluating temperature regulation by field-active ectotherms - The fallacy of the inappropriate question. Am. Nat. 142: 796-818. doi:10. $1086 / 285573$.

Huey, R.B. 1991. Physiological consequences of habitat selection. Am. Nat. 137: S91-S115. doi:10.1086/285141.

Huey, R.B., Hertz, P.E., and Sinervo, B. 2003. Behavioral drive versus behavioral inertia in evolution: a null model approach. Am. Nat. 161: 357-366. doi:10.1086/346135. PMID: 12699218.

Irschick, D.J., and Losos, J.B. 1999. Do lizards avoid habitat in which performance is submaximal? The relationship between sprinting capabilities and structural habitat use in Caribbean anoles. Am. Nat. 154: 293-305. doi:10.1086/303239. PMID: 10506545 .

Irschick, D.J., Carlisle, E., Elstrott, J., Ramos, M., Buckley, C., Vanhooydonck, B., Meyers, J., and Herrel, A. 2005. A comparison of habitat use, morphology, clinging performance and escape behavior among two divergent green anole lizard (Anolis carolinensis) populations. Biol. J. Linn. Soc. 85: 223-234. doi:10.1111/j.1095-8312.2005.00487.x.

Jenssen, T.A. 1973. Shift in the structural habitat of Anolis opalinus due to congeneric competition. Ecology, 54: 863-869. doi:10.2307/1935681.

Lister, B.C. 1976. The nature of niche expansion in West Indian Anolis lizards. II: Evolutionary components. Evolution, 30: 677-692. doi:10.2307/2407809.

Losos, J.B. 1990a. Ecomorphology, performance capability, and 
scaling of West Indian Anolis lizards: an evolutionary synthesis. Ecol. Monogr. 60: 369-388. doi:10.2307/1943062.

Losos, J.B. 1990 b. Concordant evolution of locomotor behaviour, display rate, and morphology in Anolis lizards. Anim. Behav. 39: 879-890.

Mattingly, W.B., and Jayne, B.D. 2004. Resource use in arboreal habitats: structure affects locomotion of four ecomorphs of Anolis lizards. Ecology, 85: 1111-1124.

Parody, J.M., and Parker, T.H. 2002. Biogeographic variation in nest placement: a case study with conservation implications. Divers. Distrib. 8: 11-20. doi:10.1046/j.1366-9516.2001.00126.x.

Pounds, J.A. 1988. Ecomorphology, locomotion, and microhabitat structure - patterns in a tropical mainland Anolis community. Ecol. Monogr. 58: 299-320. doi:10.2307/1942542.

Rand, A.S. 1964. Ecological distribution in anoline lizards of Puerto Rico. Ecology, 45: 745-752. doi:10.2307/1934922.

Rand, A.S. 1967. The ecological distribution of the anoline lizards around Kingston, Jamaica. Breviora, 272: 1-18.

Rivero, J.A. 1998. Los anfibios y reptiles de Puerto Rico. 2nd ed. Editorial de la Universidad de Puerto Rico, San Juan.

Rodríguez-Robles, J.A., Leal, M., and Losos, J.B. 2005. Habitat selection by the Puerto Rican yellow-chinned anole, Anolis gundlachi. Can. J. Zool. 83: 983-988.

Schoener, T.W. 1975. Presence and absence of habitat shift in some widespread lizard species. Ecol. Monogr. 45: 233-258. doi:10.2307/1942423.

Schoener, T.W., and Schoener, A. 1971a. Structural habitats of West Indian Anolis lizards. I. Jamaica. Breviora, 368: 1-53.

Schoener, T.W., and Schoener, A. 1971b. Structural habitats of West Indian Anolis lizards. II. Puerto Rican Uplands. Breviora, 375: $1-39$.

Scott, N.J., Jr., Wilson, D.E., Jones, C., and Andrews, R.M. 1976. The choice of perch dimensions by lizards of the genus Anolis (Reptilia, Lacertillia, Iguanidae). J. Herpetol. 10: 75-84.

Tabachnick, B.G., and Fidell, L.S. 2001. Using Multivariate Statistics. Allyn \& Bacon, Needham Heights, Mass.

Väli, Ü., Treinys, R., and Lõhmus, A. 2004. Geographical variation in macrohabitat use and preferences of the Lesser Spotted Eagle Aquila pomarina. Ibis, 146: 661-671. doi:10.1111/j.1474-919x. 2004.00300.x.

Williams, E.E. 1969. The ecology of colonization as seen in the zoogeography of anoline lizards on small islands. Q. Rev. Biol. 44: 345-389. doi:10.1086/406245.

Williams, E.E. 1983. Ecomorphs, faunas, island size, and diverse end points in island radiations of Anolis. In Lizard ecology. Edited by R.B. Huey, E.R. Pianka, and T.W. Schoener. Harvard University Press, Cambridge. pp. 326-370.

\section{Appendix A}

\section{Derivation of visibility formula}

For any triangle with sides $a, b$, and $c$ and where angle $A$ opposes side $a, a^{2}=b^{2}+c^{2} \cos A$.
Likewise, for an isosceles triangle where two sides have length $d$ and $\Theta$ is the angle opposing side $l$ (Fig. A1), $l^{2}=2 d^{2}-2 d^{2} \cos \Theta$.

Solving this formula for $\Theta$ gives the following:

$$
\Theta=\arccos \left[1-\frac{l^{2}}{2 d^{2}}\right]
$$

To measure visibility for a lizard's perch, we use a circle with radius $0.5 \mathrm{~m}$ centered on the lizard's head. We wish to determine the portion of that circle's circumference (i.e., the arc length) that the lizard can see. Because a circle is a $360^{\circ}$ arc, the proportion of the circle blocked by any object with diameter $l$ and at a distance $d$ from the center of the circle (and the position of the lizard's head) is found by the equation

$$
s=\frac{\Theta}{360^{\circ}}
$$

After calculating $s$ for each obstructing object within the circle, all $s$ are summed and subtracted from 1 to give a measure of the percentage of the circle's circumference that the lizard can see from its perch, i.e., its visibility.

Fig. A1. Isosceles triangle in which two sides have length $d$ and the third has length $l$, and $\Theta$ is the angle opposing side $l$. The apex of the triangle is at the center of the circle, and $s$ is the arc of the circle defined by angle $\Theta$.

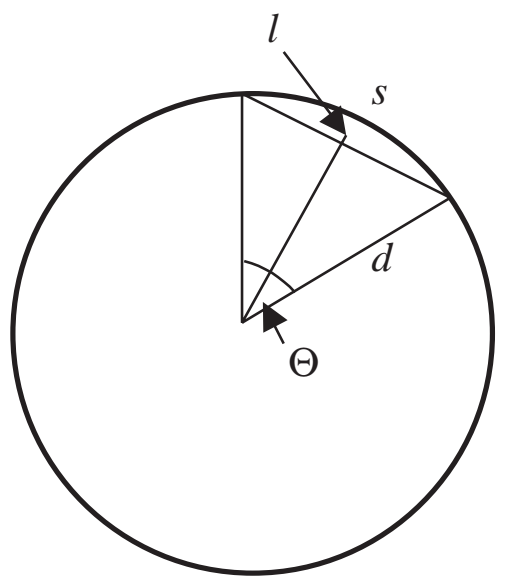

